\title{
JOINING OF MG ALLOY AZ31B BY SELECTED TECHNOLOGIES
}

\author{
Tomáš Kramár ${ }^{a, *}$, Petr Vondrouša ${ }^{a}$, Miroslav Jáña ${ }^{b}$, Tomáš $\operatorname{Kupec}^{b}$ \\ ${ }^{a}$ Czech Technical University in Prague, Faculty of Mechanical Engineering, Technická 4, 16607 Praha 6, Czech \\ Republic \\ b Slovak University of Technology in Bratislava, Faculty of Materials Science and Technology in Trnava, Jána \\ Bottu 2781/25, 917 24 Trnava, Slovakia \\ * corresponding author: tomas.kramar@fs.cvut.cz
}

\begin{abstract}
This contribution presents metallurgical joining of $\mathrm{Mg}$ alloy $\mathrm{AZ} 31 \mathrm{~B}$ by several technologies - Friction Stir Welding - FSW, Laser Beam Welding - LBW, soldering and their mutual comparison. The difficulty of joining $\mathrm{Mg}$ alloys is connected with the strong $\mathrm{MgO}$ layer, low ductility of the weld metal (WM), a presence of intermetallic phases connected with the hardness increase. To successfully join $\mathrm{Mg}$ alloys, a precise setting of welding parameters is needed. The welds are susceptible to low mechanical properties as all samples fractured at WM. From the tested methods, laser beam welding proved the best results, because laser welding is the fastest and weld strength reached the highest values, i.e. $87 \%$ of BM (base metal) strength.
\end{abstract}

KEYWORDS: Mg alloy, AZ31, soldering, FSW, LBW, intermetallic phase.

\section{INTRODUCTION}

The importance of magnesium and its alloys rapidly increased in the last years, due to the increasing demand on low weight constructions, especially in automotive and aerospace industry, due to energy consumption and environmental issues. Commercially used $\mathrm{Mg}$ alloys have a specific density,t approx. $1.7 \mathrm{~g} \cdot \mathrm{cm}^{-3}$, which is $35 \%$ lower than the density of $\mathrm{Al}$ alloys and $75 \%$ lower than the one of steel. With the increase of usage of $\mathrm{Mg}$ alloys, there is a high need of a proper method of strong metallurgical joining of $\mathrm{Mg}$ alloys, which is an objective of an extensive research in the world. Weldability of $\mathrm{Mg}$ and its alloys is similar to that of aluminium alloys, which is described in [1, 2]. The literature survey shows limitations of each joining technology, so in this research, we will aim to make a comparison and evaluation of the best available from the selected technologies. For comparison, in this research, we have selected the soldering, friction stir welding process, and laser beam welding.

\section{LiteRATURE SURVEY}

$\mathrm{Mg}$ alloys can be readily brazed, yet, at higher temperatures, they rapidly lose their mechanical properties. e.g. alloy AZ31B loses mechanical properties during brazing at a temperature of $595^{\circ} \mathrm{C}$, losing $8 \%$ of its tensile strength and $35 \%$ of its original ductility. Thus low melting temperature solders are recommended for Mg alloys, e.g. Zn based solders [3 5]. A high thermal conductivity of $\mathrm{Mg}$ alloys causes wide $\mathrm{HAZ}$ during the welding and soldering at elevated temperatures 6]. During soldering, the inert atmosphere (Ar, He) is also recommended.

The technology of Friction Stir Welding (FSW) was developed by Thomas Wayne in TWI, UK 1991.
FSW is easily used on light alloys and can be easily automated. The FSW process offers many advantages in comparison with fusion methods of welding [6] .

Laser Beam Welding (LBW) is widely used, because of its speed, precision and effectiveness, but it presents difficulties, when light alloys are considered. Magnesium alloys possess certain characteristics negatively influencing the LBW. During the LBW of Mg alloys, some processing problems and weld defects can be encountered, such as an unstable weld pool and solidification cracking. Nonetheless, crack-free laser welded joints, with a low porosity and a good surface quality, can be achieved using appropriate laser processing conditions [7. It should be welded in protective atmosphere or vacuum as it is very reactive.

\section{EXPERIMENT}

The Mg alloy AZ31 in a form of a rolled sheet was used. This alloy is non-hardenable, its composition and properties are in tables 1,2

Different joining technologies have been used and finally compared: Soldering, Friction Stir Welding (FSW) and Laser Beam Welding (LBW).

\subsection{SOLDERING}

A zinc based solder alloyed with $\mathrm{Al}$ designed for soldering of $\mathrm{Mg}$ alloys was used. Zinc interferes with the oxide layer on the surface of the soldered $\mathrm{Mg}$ material, accelerates soldering time, decreases number of imperfections in soldered joint and increases strength [3, 4]. The recommended and used solder was eutectic solder ZnAl5. The microstructure of the solder is a solid solution $\beta$-Zn phase with a dendritic structure. The melting temperature is $382^{\circ} \mathrm{C}$ according to the phase diagram. The DSC proved that the solder eutectic composition is melting at $380.5^{\circ} \mathrm{C}$. 


\begin{tabular}{l|ccccc}
\hline Elements & $\mathrm{Al}$ & $\mathrm{Mn}$ & $\mathrm{Zn}$ & $\mathrm{Si}$ & $\mathrm{Mg}$ \\
\hline Wt. $\%$ & $2.5-3.5$ & 0.4 & $0.6-1.4$ & 0.1 & Bal. \\
\hline
\end{tabular}

TABle 1. Chemical composition of Mg alloy AZ31B [8].

\begin{tabular}{lc}
\hline Elongation & $15 \%$ \\
Tensile strength & $290 \mathrm{MPa}$ \\
Fatigue strength & $97 \mathrm{MPa}$ \\
Yield strength & $221 \mathrm{MPa}$ \\
Young's modulus of elasticity & $45 \mathrm{GPa}$ \\
\hline
\end{tabular}

TABLE 2. Mechanical properties of Mg alloy AZ31B [8].

The most effective flux to solder Mg alloys AZ31B is based on chlorides $\mathrm{CaCl}_{2}, \mathrm{KCl}, \mathrm{LiCl}, \mathrm{NaCl}$ with different ratios. We used a two-compound flux with a composition $\mathrm{LiCl}+\mathrm{KCl}$ in ratio adapted to the melting temperature of the suggested solder. According to the diagram $\mathrm{LiCl}-\mathrm{KCl}$, an eutectic composition of the flux with a melting temperature of $353^{\circ} \mathrm{C}$ was assumed, which should be suitable to soldering by the eutectic solder ZnAl5. The soldering properties of the solder and flux were tested in a muffle furnace. Differential Scanning Calorimetry analysis (DSC) of the solder was done. Soldering was performed at a temperature of $430{ }^{\circ} \mathrm{C}$ for 5 min. After soldering, the light microscopy, EDX, of joints was done.

\subsection{FSW}

The other possibility of joining of $\mathrm{Mg}$ alloy is the solid state welding by the FSW method. Between the main welding parameters of the FSW method belong: load, revolutions of the tool, welding speed, angle of tool inclination and type of welding tool. In our experiment, three types of welding tools with a different pin geometry (inclination of pin) were selected. Tool steel AISI H13 (4Cr5MoSiV1) was used as the material for tools. Welded joints were performed in a cooperation with VÚZ - PI Bratislava SR, which is equipped with the welding device type FSW - LM - 060. The welding material was AZ31B, thickness of $6 \mathrm{~mm}$, the type of welded joints was butt weld.

\subsection{LBW}

Another option of metallurgical joining of $\mathrm{Mg}$ alloys is the laser beam welding (LBW). The disc laser TruDisk 4002in property of MTF in Trnava with max. power $2 \mathrm{~kW}$ and wave length $\lambda=1.03 \mu \mathrm{m}$ was used. Disc lasers are characterized by a high quality of beam, which is in a range from 2 to $8 \mathrm{~mm} \cdot \mathrm{mrad}$, the beam waist radius $\omega_{0}=0.2 \mathrm{~mm}$.

The laser beam absorptivity is very low for light alloys, i.e. the low absorptivity (high reflectivity) of $\mathrm{Mg}$ makes the LBW problematic. The absorption of the laser beam by the material can be increased, for example, by surface treatment, by grinding, by roughening, by creation of cover layer, by painting, by multiple laser infliction, double crossing of beam etc.

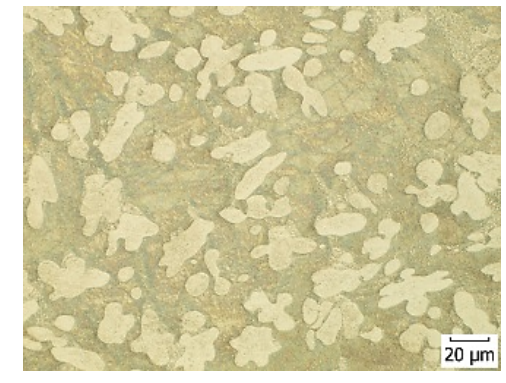

(A).

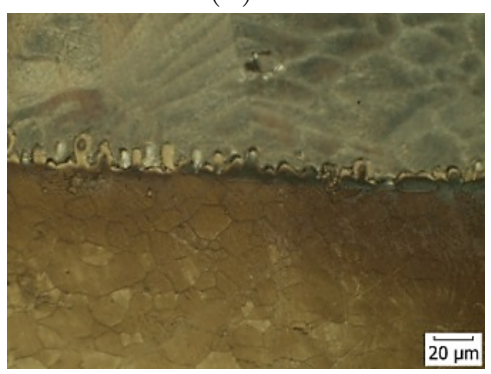

(B).

Figure 1. Microstructure a) solder ZnAl5; b) interface solder - BM.

In our experiment, many surface modifications, which are commonly used in practice for laser beam welding were performed. The tried surface modifications were:

(1.) Polished surface - surface was cleaned and polished to high shine (final surface modifications to improve the appearance of the product) $\mathrm{Ra}=0.17 \mu \mathrm{m}$

(2.) Surface grinding to eliminate the oxidic layer (it is the most often preparation of a surface before welding of any oxidized surface $\mathrm{Ra}=0.36 \mu \mathrm{m}$

(3.) Carbon sputtered - sputtering of graphite on the surface of the welded material, (thickness approx. $5 \mu \mathrm{m})$

(4.) Surface preheated by laser - just before welding, the surface is preheated by a laser beam of a lower power $P=500 \mathrm{~W}$ (this procedure is utilized by lasers with a low power, preheat temp. approx. $\left.200{ }^{\circ} \mathrm{C}\right)$

(5.) Roughened surface - to reach high surface roughness (its purpose is to reduce reflections and increase the absorption of the laser beam) $\mathrm{Ra}=3.41 \mu \mathrm{m}$

(6.) Black painted - surface painted by black marker.

\section{Results}

\subsection{SOLDERING}

The soldered joint eutectic structure, solid solution $\beta$-Zn of solder, is visible in figure 1 a The overall joint is in figure 1b. Base metal AZ31B keeps the original grain size, the HAZ is negligible. At the interface of the solder and BM, a diffusion into the $\mathrm{BM}$ and a creation and growth of intermetallic phases into the solder was observed. The width of the $\mathrm{Zn}$ diffusion into 


\begin{tabular}{lccccc}
\hline No. & $\begin{array}{c}T \\
{\left[{ }^{\circ} \mathrm{C}\right]}\end{array}$ & $\begin{array}{c}S_{0} \\
{\left[\mathrm{~mm}^{2}\right]}\end{array}$ & $\begin{array}{c}F_{m} \\
{[\mathrm{kN}]}\end{array}$ & $\begin{array}{c}R_{m} \\
{[\mathrm{MPa}]}\end{array}$ & $\begin{array}{c}A \\
{[\%]}\end{array}$ \\
\hline 1 & 20 & 111.0 & 15.54 & 140 & 4.1 \\
2 & 20 & 111.6 & 13.95 & 125 & 3.7 \\
3 & 20 & 111.6 & 17.30 & 155 & 4.5 \\
\hline
\end{tabular}

TABLE 3. Values of ultimate tensile strength and ductility of FSW joint.

AZ31 was approximately $7 \mu \mathrm{m}$. Intermetallic phases along the joint boundary growing into the solder were approx. $15 \mu \mathrm{m}$ thick and they were all along the interface. Phases $\mathrm{Mg}_{17} \mathrm{Al}_{12}$ and $\mathrm{Mg}_{7} \mathrm{Zn}_{3}$ were found, these were created by the eutectic reaction. The precipitation of intermetallic phases was confirmed by simulated phase diagrams calculated in Thermo-Calc software together with the EDX analysis. The growth of these intermetallic phases causes a brittleness of the joint. The soldered joint was formed by a ternary eutectic structure $\mathrm{Mg}_{32}(\mathrm{Zn}, \mathrm{Al})_{49}$ and by a saturated solid solution $\alpha-\mathrm{Mg}$ containing $\mathrm{Zn}$ and $\mathrm{Al}$. The presence of intermetallics is also supported by an evidence in the literature [3].

By Energy Dispersive X-ray Spectroscopy (EDX microanalysis), shown at Figure 2 it was determined that the chemical composition in the area of the soldered joint interface has $\mathrm{Mg} 81.8$ wt. \%, Al 2.47\%, Zn $15.73 \%$. In comparison with original solder $\mathrm{Zn}$ 95 wt. $\%$ and $\mathrm{Al} 5 \%$ it can be seen, that during the soldering, AZ31B strongly dissolved into the solder. The result of this is an increased content of $\mathrm{Mg}$ in the soldered area.

A difference in microhardness between the base material, intermetallic phases and solder was found. The intermetallic phase at the joint boundary $\mathrm{Mg}_{17} \mathrm{Al}_{12}$ hardness reaches a value of $272 \mathrm{HV}$, the solder has $160 \mathrm{HV}$ and the base metal has about 50-60 HV. This could be the reason of the joint brittleness.

By fractography, the fracture areas of soldered joints were evaluated. Cracks were present in the solder and a porosity was observed in the majority of the fracture area. The fracture area was covered by oxides, namely oxide $\mathrm{MgO}$, proved by the EDX. A growth of dendrites $\beta-\mathrm{Zn}$ (Figure 3 ) at the wall of the cavity was found. A high content of $\mathrm{MgO}$ oxides, presence of the flux on the fracture area, a porosity of the solder and growth of the intermetallic phase $\mathrm{Mg}_{17} \mathrm{Al}_{12}$ significantly influenced the mechanical properties of the joint.

\subsection{FSW}

An example of the welded joint is in Figure 4- it was done by a tool with an angle of the pin inclination of $6^{\circ}$ at welding parameters: load of $38 \mathrm{kN}$, spindle speed of $600 \mathrm{rpm}$, welding speed of $60 \mathrm{~mm} \cdot \mathrm{min}^{-1}$, tool tilt angle of $3^{\circ}$. The joint was evaluated by light microscopy (Figure 5) by microhardness HV0.1 (Figure 6) and by tensile test (Table 3).

\subsection{LBW}

The influence of the surface modifications was evaluated on bead on plate welds, results are shown in Figure 7. The highest difference was between the polished surface and the black painted, the polished having the highest reflectivity, the black painted having the highest absorptivity, the difference in the weld depth was almost $1 \mathrm{~mm}(33 \%)$ for $P=2 \mathrm{~kW}$ and power density $3.2 \cdot 10^{6} \mathrm{~W} \cdot \mathrm{cm}^{-2}$.

The position of the laser focal point has an equally significant influence on the process and weld quality. The position of the focal point should be adjusted depending on the desired results, e.g. achieving of maximum depth of the weld, or the best process stability. By proper adjusting of the focal position, it is possible to affect the width and depth of weld. Figure 8 shows the depth of the weld in dependence on the position of the focal point for $P=1.5 \mathrm{~kW}$. The laser power was set below $\max$ power (i.e. $2 \mathrm{~kW}$ ), because the $3 \mathrm{~mm}$ thick sheets were to be welded with a maximum of $2 \mathrm{~kW}$ later on. Changing the focal position from a negative position $(-3 \mathrm{~mm}$ under the material surface) to a positive position $(+5 \mathrm{~mm}$ above the surface) significantly changed the shape and surface of the weld by altering the weld metal flow. The best surface quality was achieved at $+2 \mathrm{~mm}$ above the surface, the deepest weld was reached at $-3 \mathrm{~mm}$. Moving the position of the focal point from negative to positive values caused a reduction of the weld depth, yet it increased the weld width and made the surface smoother.

In Figure 9, an influence of the welding speed on the weld geometry at $1.5 \mathrm{~kW}$ is shown. The reasons for this experiment is that expectably, higher welding speeds leads to a lower heat input, thus to finer grain structure [5], which expectedly improves mechanical properties and is also more economical.

It is known that $\mathrm{Mg}$ alloys are susceptible to sublimation of alloying elements [5], mainly $\mathrm{Zn}$ and the decrease of mechanical properties. From the EDX analysis (Fig. 10, no decrease of any alloying elements caused by the laser welding was observed. A high surface density of the laser radiation, high welding speed resulting in a narrow weld and a very low HAZ enabled no sublimation of $\mathrm{Zn}$ in WM.

Laser welded samples and base metal samples were tested for tensile strength. All welds fractured at the WM or fusion boundary. The ultimate tensile strength was high, $185 \mathrm{MPa}$, lower than BM by $36 \%$, but a high decrease in ductility of the welded sample was noted. All welded samples cracked in WM and, together with the limited ductility, it signalizes negative phase changes caused by the welding.

The average hardness of WM is 53 HV0.1 The average values of WM (53 HV) and BM $(51 \mathrm{HV})$ are close, but the change of the microstructure caused by the welding was noticeable by the higher scatter of hardness values in WM compared to BM. It is possible, that a precipitation of $\mathrm{Mg}_{17} \mathrm{Al}_{12}$ occurred in WM. 

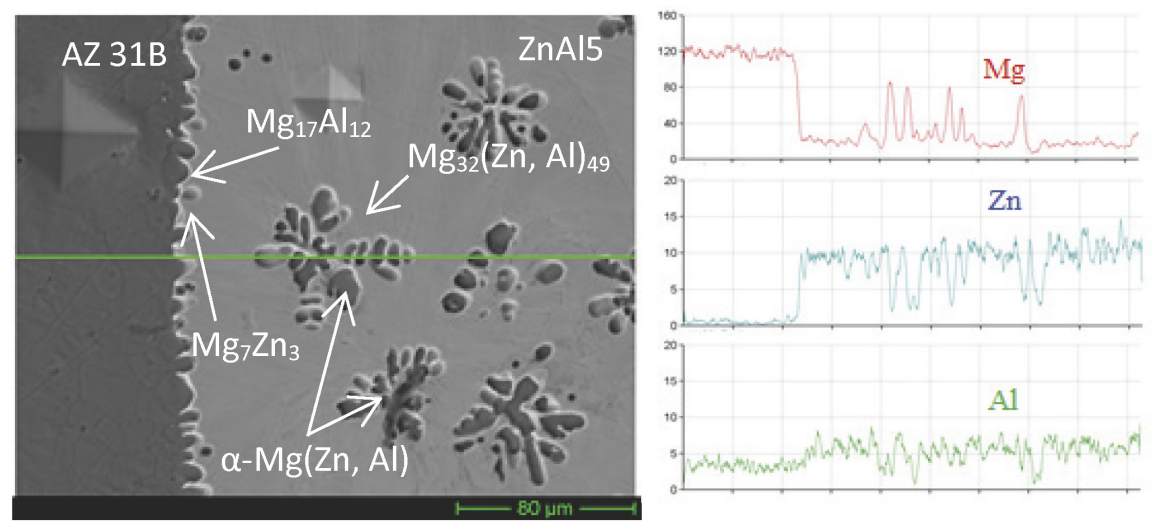

FIgURE 2. Optical microscopy and line analysis across substrate AZ31 - solder ZnAl5 interface.
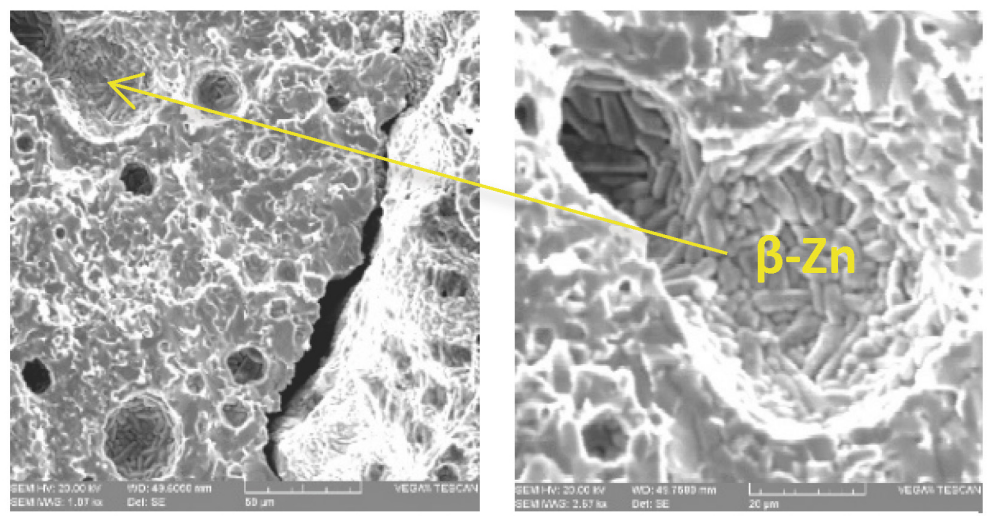

Figure 3. Dendrites $\beta$-Zn in eutectic solder ZnAl5.

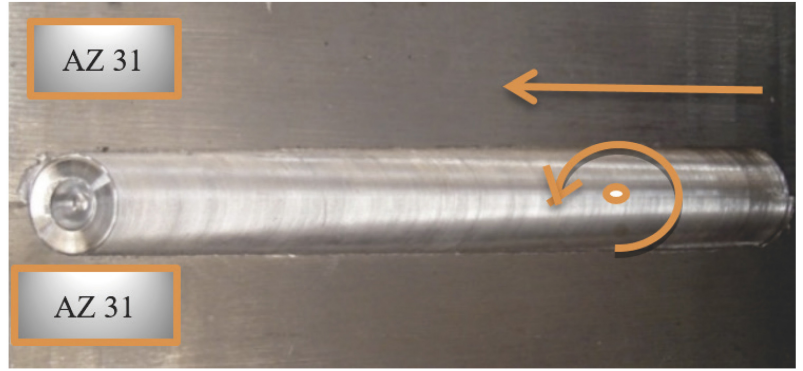

Figure 4. Welded joint of Mg alloy type AZ31.

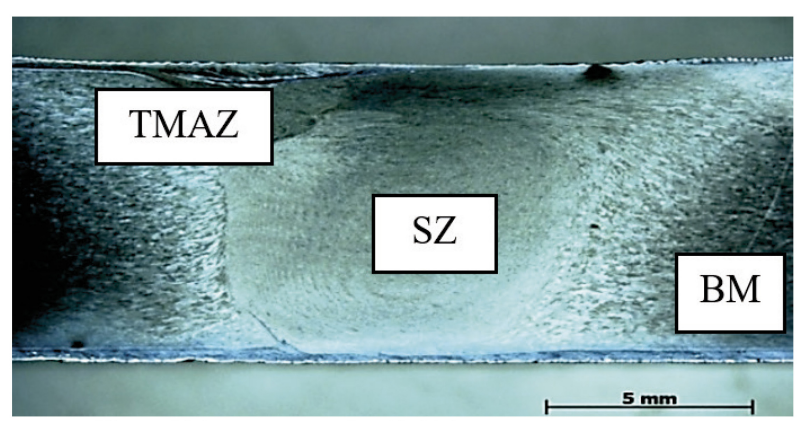

FiguRE 5. Macrostructure of welded joint.

\section{Conclusion}

In present, GMAW and GTAW are the main welding methods for $\mathrm{Mg}$ alloys, especially for a repair of casting defects. However, a low welding speed and the resulting wide Heat Affected Zone cause a decrease of alloying elements by sublimation, high distortion and low mechanical properties of welds [5].

In this contribution, 3 joining technologies especially suitable for $\mathrm{Mg}$ alloys are presented - soldering, FSW and LBW. Soldering means not fusing the base material, thus the heat input is very limited, so the deformations and stresses are kept low. The process is easy to automate. The FSW is also done under the melting temperature, as it occurs at a plasticized metal state. The plastic deformation is strengthening the metal and breaks down oxide layer. The LBW is a fusion welding technology using a highly concentrated weld beam, yet the fused volume of material is extremely small, so the weld and heat affected zones are small. It is also easy to automate.

Yet, for the tested technologies, we have discovered many drawbacks. They are as follows:

The soldering was done at $430{ }^{\circ} \mathrm{C}$ for 5 min using a recommended solder $\mathrm{ZnAl5}$. The resultant structure of the soldered joint consists of an eutectic ternary structure $\operatorname{Mg}_{32}(\mathrm{Zn}, \mathrm{Al})_{49}$ and a solid solution $\alpha-M g$ containing elements $\mathrm{Zn}$ and $\mathrm{Al}$. The oxidic layer $\mathrm{MgO}$ created at surface of the alloy with the melting tem- 

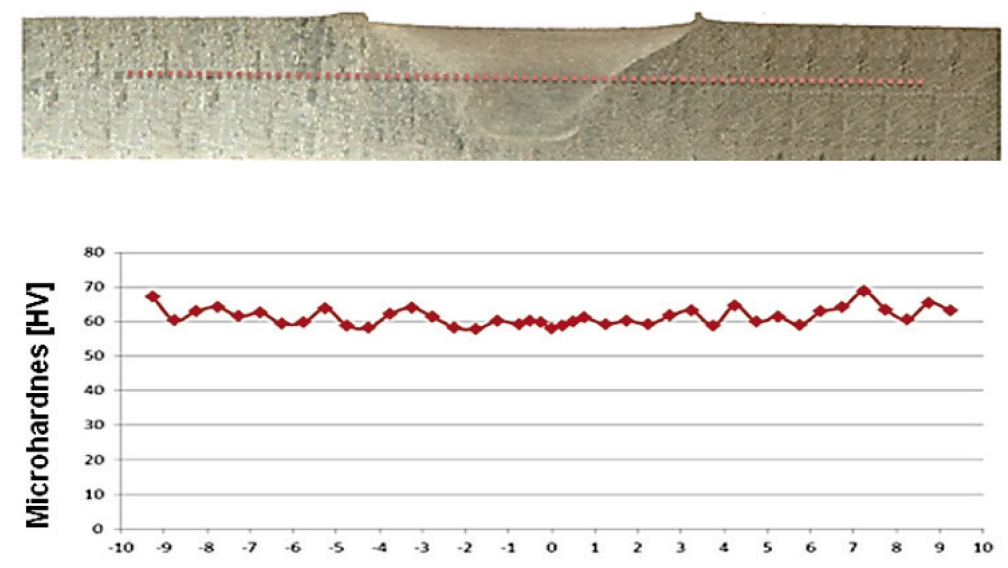

Distance from the axis [mm]

FIGURE 6. Microhardness course across the FSW joint.

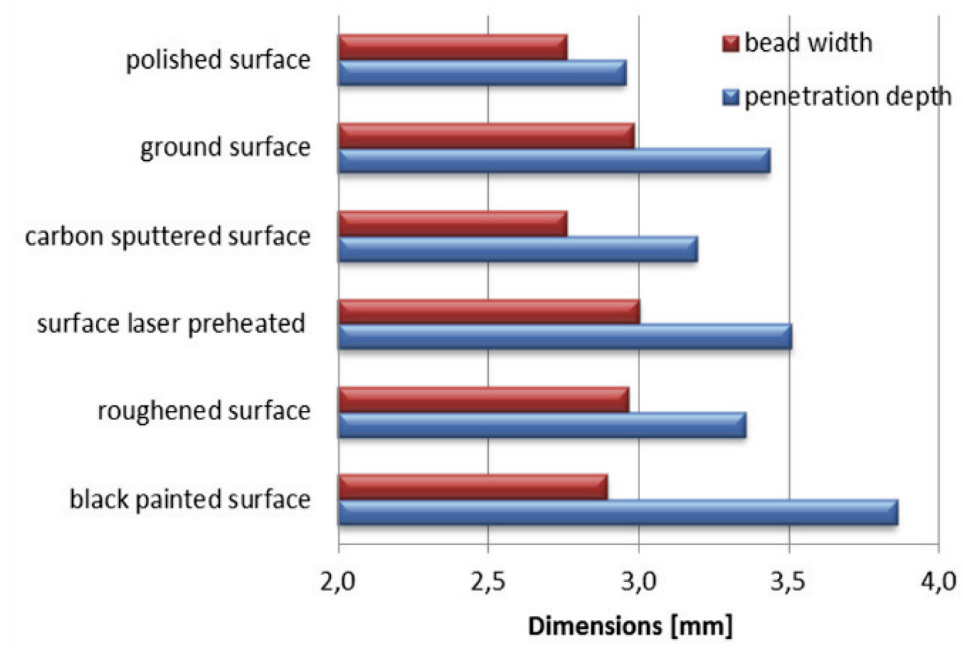

Figure 7. Weld width and penetration depth; disc laser, $P=2 \mathrm{~kW}, v=20 \mathrm{~mm} \cdot \mathrm{s}^{-1}$, dif. surface pretreatments.

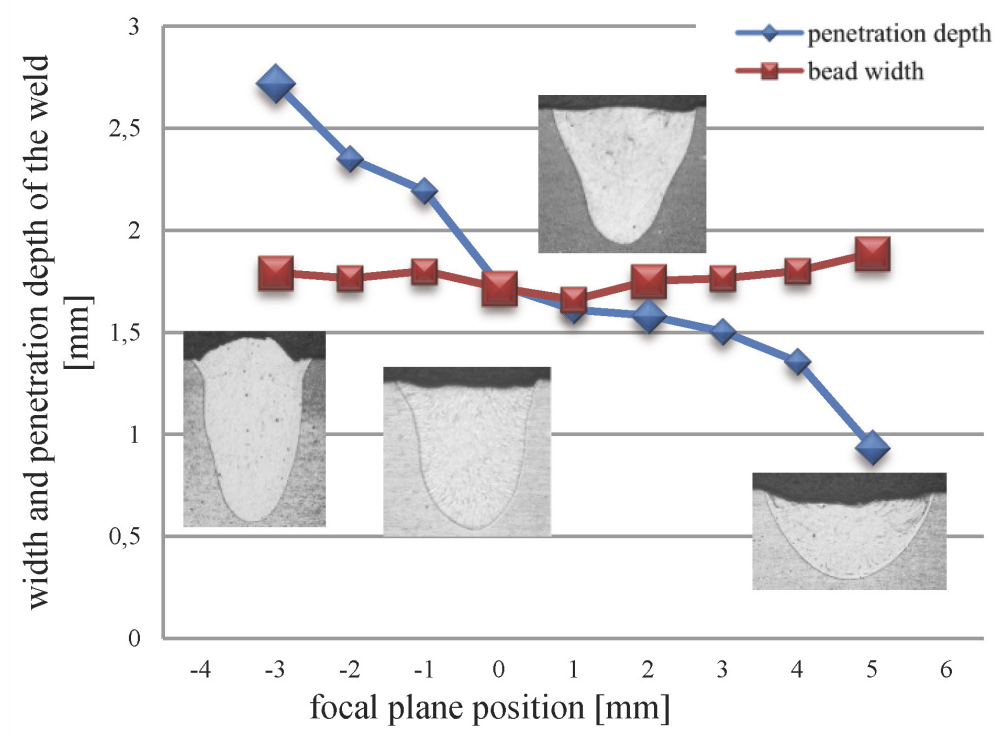

Figure 8. Influence of focal plane (spot) position on weld depth and width; power $1.5 \mathrm{~kW}$, speed $80 \mathrm{~mm} \cdot \mathrm{s}^{-1}$. 


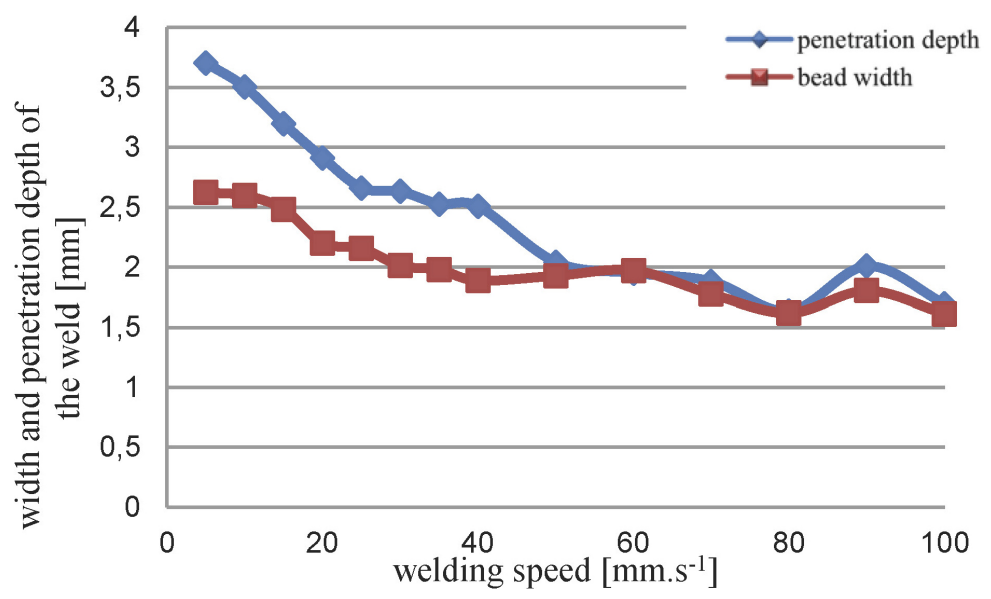

Figure 9. Influence of welding speed on depth and width of weld, $P=1.5 \mathrm{~kW}, f=0 \mathrm{~mm}$.

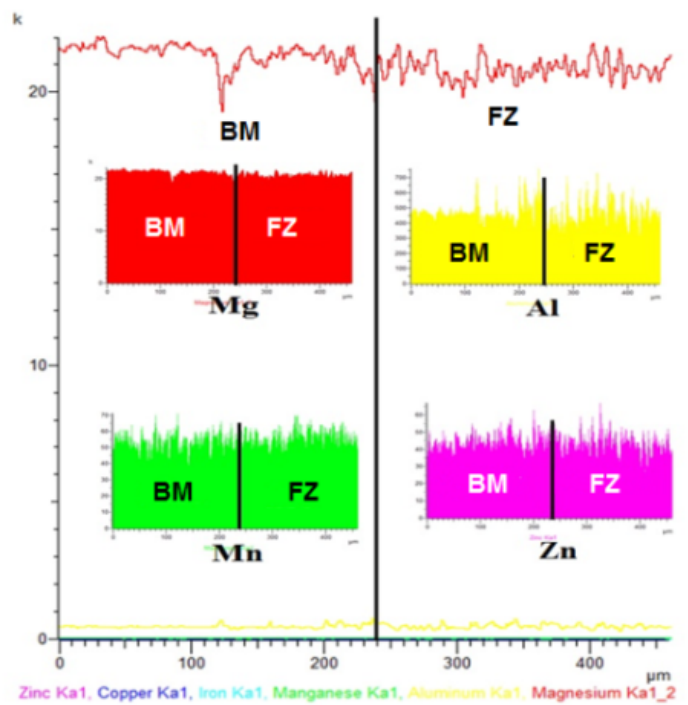

Figure 10. EDX line analysis of laser weld accross the weld, fusion zone.

perature of $2200^{\circ} \mathrm{C}$ proved difficult to remove by the soldering flux. The soldered joints thus contained oxides $\mathrm{MgO}$, that lead to a joint brittleness. These oxides were easily visible at the fractured surface. The long time of soldering led to a creation of intermetallics $\mathrm{Mg}_{17} \mathrm{Al}_{12}$ and $\mathrm{Mg}_{7} \mathrm{Zn}_{3}$ with a hardness $272 \mathrm{HV} 0.1$ and 311 HV0.1. These phases have significantly different properties than the BM and function as a stress concentrator. To improve the soldering, a proper removal of the oxidic layer must be done.

The best welded joint, created by the FSW process, was fabricated with a $6^{\circ}$ welding tool with the following parameters: downward force $38 \mathrm{kN}$, tool revolutions $600 \mathrm{RPM}$, welding speed $60 \mathrm{~mm} / \mathrm{min}$., tool tilt angle $3^{\circ}$. The microhardness values varied in the range from 59 to $70 \mathrm{HV}$. Similar microhardness values were measured in the TMAZ and BM. The strength of the welded joints achieved was 55 to $60 \%$ of the value of the base metal. Setting up the FSW is an extremely complicated task, because of many process parameters - tool geometry, clamping and tool forces etc. It is expected that optimum parameters would lead to an acceptable weld strength.

The LBW is a fusion welding having very high welding speed, yet its speed enabled a creation of fine grain structure in the WM and HAZ. These fine grains and small dendrites improve many mechanical properties (Hall-Petch equation). The problem of laser beam's reflectivity was suppressed by a suitable surface pretreatment. In our experiment, a black painted surface, in a comparison with a polished surface, led to an increase of the weld depth by $33 \%$. The position of the focal spot has a big influence not only on the weld's shape, but also on the surface quality. The welding speed is another influential parameter - at low welding speeds, the vapour plume, ejected from the keyhole, is defocusing the beam. The sublimation of low evaporation constituents (mainly $\mathrm{Zn}$ ) was not noted for LBW, probably because its high welding speed.

The weldability of $\mathrm{Mg}$ alloys is problematic as it was shown in our research. The optimum welds can only be created when the perfect welding conditions and parameters are set up. For Mg alloys, the parameters of the welding technique must be precisely researched. Also, the combination of respective technologies can lead to optimum results, e.g. the FSW with a laser preheating.

\section{ACKNOWLEDGEMENTS}

We would like to express our gratitude for the support of the grant project SGS 13/187/OKH2/3T/12 and to the colleague Martin Sahul, Faculty of Materials Science and Technology in Trnava, for the execution of the EDX analysis.

\section{REFERENCES}

[1] L. Kolarik, K. Kovanda, P. Vondrous, J. Dunovsky. Houldcroft weldability test of aluminium alloy EN AW 6082 T6. Scientia Agriculturae Bohemica 43:14-21, 2012. DOI:10.17973/MMSJ.2011_07_201105

[2] L. Kolarik, M. Kolarikova, K. Kovanda, et al. Influence of repair welding on weld quality of $\mathrm{Al}$ alloy EN AW 6082-T6. In Metal 2012: 21th international 
conference on metallurgy and materials, pp. 1504-1510. Tanger Ltd., 2012.

[3] L. Mordike, P. Wiesner. Fügen von

Magnesiumwerkstoffen. In Hardcover DVS - Verlag für Schweißen und verwandte Verfahren, p. 232. 2005.

[4] H. Beneke. Lexikon der Korrosion und des Korrosionsschutzes. Vulkan-Verlag, 2000.

[5] M. Sahul, M. Sahul, J. Lokaj. Effect of surface layer on the properties of AZ31 magnesium alloy welded joints. Materials Today: Proceedings 3:1150-1155, 2016. DOI:10.1016/j.matpr.2016.03.015.

[6] R. Mishra, W. Mahoney (eds.). Friction Stir Welding and Processing. ASM International, Ohio, USA, 2007.
[7] X. Cao, M. Jahazi, J. Immarigeon, W. Wallace. A review of laser welding techniques for magnesium alloys. Journal of Materials Processing Technology 171:188204, 2006. DOI:10.1016/j.jmatprotec.2005.06.068

[8] J. Hirsch, T. Al-Samman. Superior light metals by texture engineering: Optimized aluminum and magnesium alloys for automotive applications. Acta Materialia 61(3):818-843, 2013. DOI:10.1016/j.actamat.2012.10.044 